\title{
Influence of IT on Productivity in Mining Industry (Case Study: Rio Tinto)
}

\author{
Rudy \\ \{rudy.lims@gmail.com\}
}

Binus Business School, Bina Nusantara University

\begin{abstract}
Global economic uncertainty has led to a decline in mining commodity prices recently. This condition has prompted mining companies to take strong steps to improve their productivity. The role of Information Technology has been studied for many years as one of the important factors for improving productivity and business performance. The purpose of this paper is to study how IT capabilities as innovation drivers in improving organizational efficiency and productivity in the mining industry. Emerging technologies have the potential to open-up a new way to manage and direct mining operations more efficiently to increase productivity, reduce costs and maximize profit.
\end{abstract}

Keywords: Information Technology, Productivity, Innovation, Business Performance

\section{Introduction}

High economic growth in Asia in early 2000, especially China and India, has driven demand for mineral and metal raw materials. The demand has rapidly increased commodity prices. During that period, the mining industry experienced high growth due to an increase production volume and an increase commodity prices. Recently, the global mining industry is facing uncertainty due to the decline of commodity prices as a result of the economic difficulties that hit uero zone and economic slowdown in China, which leads to decline in performance and lack of capital for most of mining companies. During the period of June 2013 to September 2014, nearly 200 mining companies in Australia went bankrupt and most are undercapitalized [1]. For survival in the midst of this uncertainty, the mining need to look at the productivity as one of the main issues. Previously when the boom period, mining just focus on effort to increase the volume of production to gain maximum profit regardless of the increase in production cost and productivity [2]. Although the company gain high profit but no followed by growth in profit margins from the growth of the business in which earning before interest and taxes (EBIT) stagnated because it was followed by an increase in other costs such as labor, fuel costs, and other costs due to higher commodity prices (Gilbertson 2012). Therefore, the level of productivity in mining industry has declined by $3.5 \%$ a year over the last decade [3] and was lower when compared to other sectors [2], [4], [5] .

Productivity is considered important because it affects the growth quality [6] and become a differentiator with competitors in the long-term [7]. There are two efforts that can be done to improve mining productivity, through short-term and long-term efforts. Short-term effort is done through the efficiency of operating costs, particularly the cost of capital expenditure and operational expenditure of the workers are the two major factors lead to declining productivity. 
While long-term effort focus on improving the capabilities and innovation to address the root causes of declining productivity.

With the development of IT today, opening the potential to a make breakthrough to enhance productivity through improving company's innovation capabilities [2]. According to [8], the IT infrastructure acts as a driving factor of innovation process, in addition to the daily operational activities. Along with the use of IT as a component for generating and implementing ideas, processes, new products and services [9]. In the next chapter will discuss the literature review, followed by a discussion about the role of IT that have a significant impact on productivity improvement of the mining industry, and the end with a conclusion.

\section{Literature Review}

\subsection{Firm Performance}

In general, the evaluation of company's ability based on the performance's achievement to identify and implement the right strategy to achive company's objectives in the context of achieving the goal [10]. The company's performance is one of the most important variables and indicators in management research [11], which allows researchers and managers to evaluate the company from time to time and compare to its competitors [12]. Managers begin to understand that a company will be successful if achieves its objectives (effectiveness) with minimal resources (efficient) to obtain optimal results.

Currently, theoretical research and empirical results on the performance of the company begin to focus on productivity and efficiency as an important aspect of the company's performance [13]. Productivity and efficiency are considered as factors that affect the growth quality [6] and become a differentiator with competitor in the long-term [7]. In the last period period, the mining industry was facing major issues related to the problem of productivity and efficiency as a result of failing commodity prices. Miners looking for ways to increase productivity by cutting the costs incurred to generate mining output or to increase output without increasing other costs [2].

Productivity is generally defined as the ratio between output and input; how the output obtained from a given input [14]. Sink dan Smith [15] defines productivity as the relationship between the output of the organization system and what is consumed to produced the output. In order to see the difference in the productivity level, it can be done by comparing the intercompany, industry or from time to time in the company. While productivity gain is defined as the ratio between the increase of output to a given input, which is generally influenced by several factors such as technology, management, skills, and working practices [16]. Efficiency refers to the relationship between the actual expenditure of resources than the expected expenditure of resources. Particularly, according to [7], the concept of efficiency is measured by how well the organization uses resources as inputs to achieve results as the output, compared to its maximum potential.

In general, productivity is measured based on the indicators of capital and labor as inputs used to generate output of goods and services. But mining has a different character compared to other industries because it is influenced by other important factor, namely non-renewable natural resources as inputs of production. Natural resources are the major input into the 
production of mining, with the changes in the quality and accessibility of deposit decline, greater commitments of capital and labor are generally needed to extract them. When deposits are deeper, more development work is needed to access the desired resources. In short, more effort is needed to produce a unit of output. Consequently, productivity in mining reflects not only changes in production efficiency, but also changes in the underlying quality and accesibility of natural resources input to mining [16].

\subsection{Firm Performance}

The role of IT capability has become more important in improving organizational performance. Some recent studies indicate that IT capability provide a basis of gaining competitive advantage. The application of IT within an organization can be traced through several stages. The initial stage refers to the support of administrative and is provided by automation, control and communication through IT. The most important stage through a transformational stage. At this stage, the IT influences, changes and provides new form of business, become strategic partner within the organization, and is focused on generating value [17].

Research shows that there is no single definition of IT Capabilty. [18] defines IT capability as a type of ability organizations have that can support the activities and work processes in the organization by arranging and bringing together other resources that are important [18]. Simillarly, [19] defines IT capability as the ability of an organization to effectively acquire, distribute, and leverage IT related resources (e.g. software, hardware and IT personnel) and to manage organization information in an integrated manner. Another different view [17] looks at capability as set of skills and knowledge related to competencies so they define IT capability as a combination of competencies (skills and knowledge) and IT resources (infrastructure) which is created by a particular organization and is implemented through activities to achieve business objectives.

\subsection{IT Capability}

The role of IT capability has become more important in improving organizational performance. Some recent studies indicate that IT capability provide a basis of gaining competitive advantage. The application of IT within an organization can be traced through several stages. The initial stage refers to the support of administrative and is provided by automation, control and communication through IT. The most important stage through a transformational stage. At this stage, the IT influences, changes and provides new form of business, become strategic partner within the organization, and is focused on generating value [17].

Research shows that there is no single definition of IT Capabilty. [18] defines IT capability as a type of ability organizations have that can support the activities and work processes in the organization by arranging and bringing together other resources that are important [18]. Simillarly, [19] defines IT capability as the ability of an organization to effectively acquire, distribute, and leverage IT related resources (e.g. software, hardware and IT personnel) and to manage organization information in an integrated manner. Another different view [17] looks at capability as set of skills and knowledge related to competencies so they define IT capability as 
a combination of competencies (skills and knowledge) and IT resources (infrastructure) which is created by a particular organization and is implemented through activities to achieve business objectives.

\section{Discussion}

Improvement of productivity is closely related to innovative thinking and the use of technology in order to provide added value. In some recent research indicates that technological development is an important driver factor for innovation [20]. This factor is required to produce a new method, process or technique [21] that needed to perform the production and innovation activity [22]. Although in general the mining regarded as the middle and low technology [23], [24] However, the use of new technologies in the mining is very important in many aspects of mining activities ranging from prospecting, extraction untill processing [23].

The mining is an industry that tends to be conservative and risk averse because basically mining has different characteristics from other industries which depend on many variables that influence it, a long process, a huge investment and covered by high risks. So considers that innovation can create a new risk for the company. Especially, high tech projects tend to be capital intesive that requiring large investments with uncertain outcomes and may not be realized in the future [25]

But, with the various uncertainty faced by mining as a result of decline in commodity prices, decline in grade deposit, health and safety, and the impact of environmental degradation requires the company to make changes in order to survive under uncertainty condition. One of the main issues is the continuous decline in productivity so the company need to find a breakthrough to improve productivity, one of it is done by utilizing IT. Several studies from 1990 to 2014 showed about the positive impact of IT on productivity [26]. Other studies that focus on the intensity of IT usage, found that companies use IT generate productivity growth higher than those which does not use IT as shown by [27] that companies use IT in US and Europe show that an accelerated growth productivity of $3.5 \%$ peryear. Similarly, a study conducted by [25] in the mining industry also showed the samething that IT has an important role in the mining industry that enables increased efficiency, productivity and at a certain moment radically change the mining process.

IT capability in the mining industry developed gradually that began in the 1970s when the IT had not been a lot of role because of the limitations of slow and expensive mainframe. Only in the $1980 \mathrm{~s}$, it began to change because of the rapid increase in the hardware and software ability as well as the emergence of personal computer (PC). In the 1990s the big jump occurred in the mining innovation through communication and sensing technologies. Mine production system was developed by utilizing the global positioning system (GPS) and automation technology, including changes in the mindset of business leaders about the importance of innovation for the company. After 2000s, global communication systems and e-commerce radically begin to transform business process in mining [25]. On a broader scale, [28] stated that digital transformation in mining industry will help to reduce 610 tonnes of CO2 emission, save 1000 lives, prevent 44000 injuries, and create a value of $\$ 320$ billion over the next decades. 
The development of technology that available today has the potential to open up a new ways to manage and direct mining operations more efficiently to increase productivity, reduce costs and maximize profit through:

\section{- Automation and remote operation}

Automation makes possible to communicate and operate equipment remotely which is widely used, especially in underground mines and hazardous environments. In addition to positive impact on the health and safety, not only it avoids humans from dangerous areas, but also increase the productivity because the equipment can move faster and cover further operation area and requires little operator to operate [29].

\section{- Asset Management}

The use of sensor in mining equipment to collect all data that covers the characteristics of the equipment will help to optimize and improve the effectiveness of the use of the equipment. As the implementation of real time monitoring system on the equipment that made Rio Tinto provides equipment maintenance cost saving of more than USD 1 billion [29].

\section{- Process Improvement}

Helping to optimize the value chain in the organization process of the extraction, processing up to sales through collaboration and coordination among various departments to improve efficiency and effectiveness. Implementation of e-procurement carried out by a consortium consisting of 15 mining companies in the wold that do global online business to business (B2B) for the procurement save money $5 \%$ to $15 \%$ [25].

\section{- Decision Making}

Adoption of IT has an impact on a more comprehensive understanding of the resource base, optimizing the flow of materials and equipments, improve the anticipation of failure, increasing mechanization through automation, and performance monitoring in rea time so it will help in decision making [3].

\section{- Accuracy}

Drilling and blasting are more accurate and faster so increase higher ore recover and profitability, improved health, safety and environmental quality employment. In addition, the use of automatic Load Haul Dump (LHD) to reduce operating and maintenance costs [25].

\section{- Health and Safety}

In terms of a range of broader health risks that are common in a mining environment. The mining has introduced many incremental innovations that have improved the safety of personnel working in inherently hazardous environments, both above and below ground. Automation will minimise the number of human operators that will need to be located on site or in close proximity to operations [29]. 


\section{IT Innovation in Rio Tinto}

Rio Tinto is one of the world leading mining group with the major work include finding, mining and and processing mineral resources 40 countries. Rio Tinto's vision is to become the sector leading global mining and metal company. To support this strategy, Rio Tinto has three strategy pillars: production at cost; value driven growth; and maximizing portfolio value [30]

In the face of increasing demand, increased production cost, skilled labour shortage and inefficiency of production. Rio Tinto Innovation \& Technology launched a program called "Mine of The Future (MOF)" in 2008 that focuses on creating a sustainable value through a holistic approach by finding a new ways to mine and extract minerals that will create the benefits such as greater efficiency, lower production cost and more attractive working conditions. The company has started to work with several mining equipment manufacturers such as Komatsu for automated truck and Atlas Copco to develop autonomous drilling solution. The development of autonomous trucks proved $10 \%$ improvement in utilised time with no incident record [31].

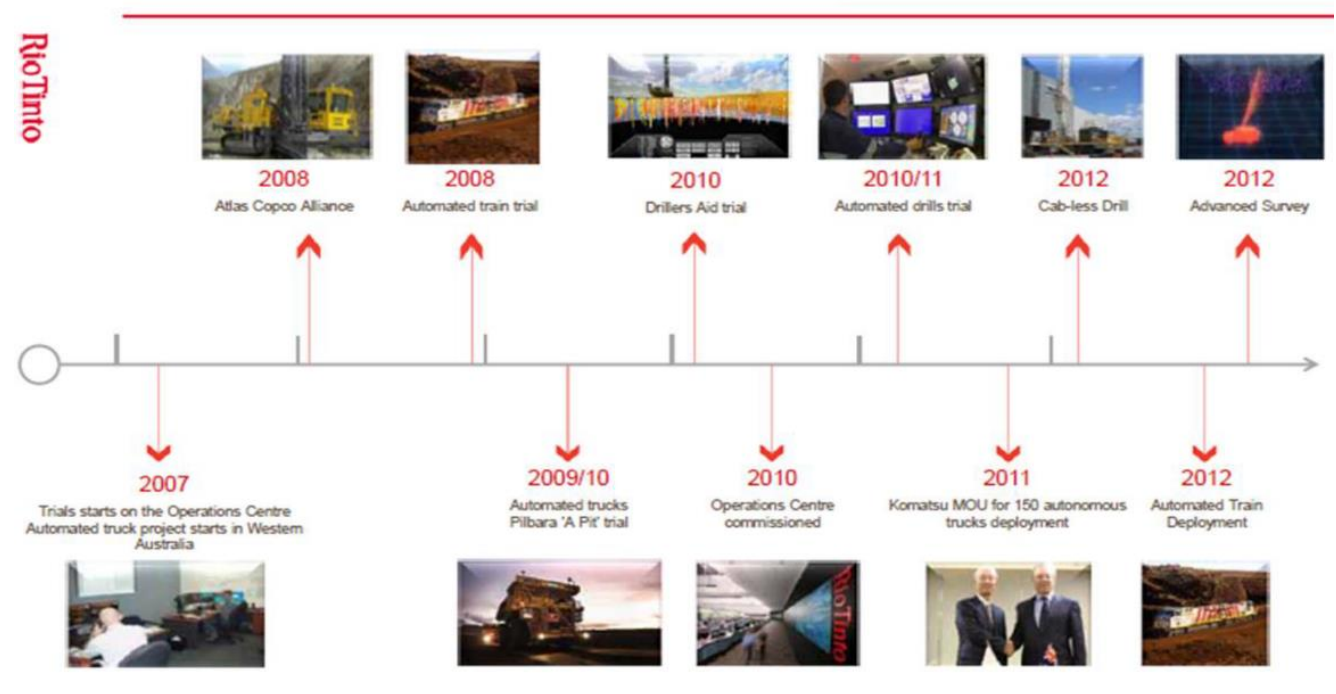

Source: [30]

Figure 1. Milestone of "Mine of The Future Programme"

Rio Tinto built an Operation centre located in Perth that enables mines, ports, and rail system to be operated from a single location. Utilization of the latest IT equipments in the mining industry, Rio Tinto uses RTVi as a tool of 3D modelling to visualize in 3D the mining sites with complementary sensors on trucks, drilling, mining equipment and processing plants to get real-time data and send it to the operating centre. Then RTVi used to visualize the data generated to perform job schedulling and deliver instructions back to the truck and drilling equipment. Results from the use of this IT equipment has increased Rio Tinto iron ore production by $2.5 \%$ and increase of 900,000 additional tons of iron ore compared to last year from one mine site only. In addition, this technology also significantly enhanced haul cycle time (load-haul-dump cycle), extend tyre life, reduce fuel usage and lower maintenance cost [32]. These benefits suggest that Autonomous System improves not only efficiency and productivity but also some social and environmental issues. RTVi is now used by nearly 1000 employees of Rio Tinto in open pit mining operations throughout the world. In addition, RTVi also provides 
drilling cost efficiency approximately $13 \%$ or $\$ 150,000$ within six weeks after the equipment is implemented. At the mining in America, RTVi reduce long queus and waiting time in shift that allows to determine when the righ time to make the turn. Thus providing an additional 16 loads for the first two hours of each shift. Then, early 2016, Rio Tinto decided to open exploration dataset for use by small mines to spread the risk of new projects and identify new opportunities as mineral prices are still under pressure.

\section{Summary}

Innovation will only happen if the company has sufficient innovation capability [33] and want to take risks to generate new ideas in building innovation accompanied by a clear vision and strategy. Particularly, the role of IT in mining has experienced the change from simply providing support to be as innovative media operation to perform transformations on various aspects of mining operation, which in turn help to increase efficiency and the productivity, as well as play a role in collecting, analyzing and using the information to be more productive.

Future study could investigate the use of new and current emerging technologies such as big data IoT, big data, and AI technology, how these technologies help mining companies to transform how the way they operate business and what are the critical success factors, especially for small and medium mining companies. For instance, establish supply chain intelligence system from the big data, it would improve sustainable supply chain management by better decision and more collaboration with suppliers, partners and the key stakeholders. Use of IoT in mining operation primarily as means of achieving cost and productivity optimization, improving safety measures and developing their artificial intelligence needs. Using vast amounts of data, such as drilling reports and geological survey, AI and machine learning can make predictions and provide recommendations on exploration, resulting in a more efficient process. AI powered predictive model will also allow mining to improve their metal processing method, through more accurate and less environmental damaging technique.

\section{References}

[1] Delloite, "Tracking the trends 2015," 2015.

[2] McKinsey\&Co, "Productivity in mining operations : Reversing the downward trend," 2015.

[3] H. Durrant-Whyte, R. Geraghty, F. Pujol, and R. Sellschop, "How digital innovation can improve mining productivity," McKinsey Co. Insights, no. November, 2015.

[4] Deloitte, "Tracking the trends 2015," 2015.

[5] Ernst \& Young, "Business risks facing mining and metals 2014-2015," EY's Glob. Min. Met. Cent., p. 34, 2014, [Online]. Available: ey.com/miningmetals.

[6] D. Galarneau and C. Dumas, "About productivity," Perspectives (Montclair)., vol. 5, no. 1, pp. 26-32, 1993.

[7] P. Sarantopoulos, L. Kioses, and G. Doukidis, "Productivity and Efficiency in Grocery Retail," 2013.

[8] M. Koskinen, J. Luomala, and P. Maaranen, "Ict-related Intangibles And Organizational Innovation: Indicators For Improving Connectedness And Flexibility," An Interdiscip. J. Humans ICT Environ., vol. 8, no. May, pp. 24-45, 2012.

[9] R. M. T. Masa'deh, "The Impact of Information Technology Infrastructure Flexibility on Firm Performance: An Empirical Study of Jordanian Public Shareholding Firms," Jordan J. Bus. Adm., vol. 9, no. 1, pp. 204-224, 2013. 
[10] R. M. Ben Zaied, H. Louati, and H. Affes, "The Relationship Between Organizational Innovations, Internal Sources of Knowledge and Organizational Performance," Int. J. Manag. Value Supply Chain., vol. 6, no. 1, pp. 53-67, 2015.

[11] C. Gavrea, L. Ilies, and R. Stegerean, "Determinants of Organizational Performance: the Case of Romania," Manag. Mark., vol. 6, no. 1, pp. 285-300, 2011.

[12] P. J. Richard, G. Johnson, T. M. Devinney, and G. S. Yip, "Measuring Organizational Performance as a Dependent Variable: Towards Methodological Best Practice,” J. Manage., vol. 35, no. 3, pp. 718-804, 2008.

[13] V. Le and C. Harvie, "Firm Performance in Vietnam: evidence from manufacturing small and medium enterprises," 2010.

[14] C. Syverson, "What Determines Productivity?," J. Econ. Lit., vol. 49, no. 2, pp. 326-365, 2011.

[15] B. Xhaferi, "Measuring Productivity," Eur. Sci. J., vol. 8, no. 12, pp. 68-80, 2012.

[16] V. Topp, L. Soames, D. Parham, and H. Bloch, "Productivity in the Mining Industry: Measurement and Interpretation," 2008.

[17] N. Pintaric and T. Bronzin, "IT Capability Review," in Central European Conference on Information and Intelligent Systems, 2013, pp. 104-110.

[18] S. Jorfi, K. Md Nor, and L. Najjar, "The Relationships Between IT Flexibility, IT-Business Strategic Alignment, and IT Capability," Int. J. Manag. Inf. Technol., vol. 3, no. 1, pp. 16-31, 2011.

[19] H. Ryu and J. Lee, "Effect of IT Capability on the Alignment between Business and Service Innovation Strategies," 2013.

[20] M. Kurkkio, J. Frishammar, T. Ejdemo, and P. Soderholm, "Mapping The Nordic Mining and Metal," 2014.

[21] A. Afuah, "Mapping technological capabilities into product markets and competitive advantage," Strateg. Manag. J., vol. 23, no. 2, pp. 171-179, 2002.

[22] J. Piana, "Innovative Technological Capabilities Accumulation in the Mining Industry in the context of Emerging Economies: Substantive and Methodological Aspects of an on-going Firm Level Empirical Research in Brazil," 2015.

[23] M. Jébrak, "Innovations in mineral exploration : Targets , methods and organization since the first globalization period," 2012.

[24] P. J. Bartos, "Is mining a high-tech industry?. Investigations into innovation and productivity advance," Resour. Policy, vol. 32, no. 4, pp. 149-158, 2007.

[25] Global-Economics-Limited, "Mining Innovation: An overview of Canada's dynamic, technologically advanced mining industry," 2001.

[26] M. Cardona, T. Kretschmer, and T. Strobel, "ICT and productivity: Conclusions from the empirical literature," Inf. Econ. Policy, vol. 25, no. 3, pp. 109-125, 2013.

[27] R. Sadun and J. Van Reenen, "EDS Innovation Research Programme," 2005.

[28] WEF, "Digital Transformation Initiative Mining and Metals Industry," World Econ. Forum, no. January, 2017.

[29] B. S. Fisher and S. Schnittger, "Autonomous and Remote Operation Technologies in the Mining Industry Benefits and Costs," Canberra, 2012.

[30] F. Marenge, J. Montgomery, M. Zaw, and Y. Y. Marey, "Rio Tinto \& Mine of the Future: Managing Strategic Resources and Operations," 2014. [Online]. Available: https://www.academia.edu/29037773/Rio_Tinto_and_Mine_of_the_Future_LB5230_Managing _Strategic_Resources_and_Operations.

[31] P. Garvey, "Rio's autonomous haul trucks quietly improving productivity in Pilbara.," Aust. Bus. Rev., pp. 4-9, 2013, [Online]. Available: http://www.theaustralian.com.au/business/in-depth/riosautonomous-haul-trucks-quietly-improving-productivity-in-pilbara/story-fni4k1kl1226627375954.

[32] ITnews, "Rio Tinto grows driverless truck fleet," iTnews, 2014, [Online]. Available: https://www.itnews.com.au/news/rio-tinto-grows-driverless-truck-fleet-382965.

[33] J. Tidd and J. Bessant, Managing Innovation Fourth Edition. Wiley, 2009. 